Jurnal ABDINUS : Jurnal Pengabdian Nusantara, 3 (1), 2019, 20-29

Available online at: http://ojs.unpkediri.ac.id/index.php/PPM

DOI: https://doi.org/10.29407/ja.v3i1.13488

\title{
Pendampingan Pembuatan Keripik Jenang Dumbleg Berbahan Dasar Jenang Dumbleg di Kecamatan Gondang Kabupaten Nganjuk
}

\author{
Dyah Nurul Afiyah $^{1^{*}}$, Riska Nurtantyo Sarbini ${ }^{2}$, Ahsin Daroini ${ }^{3}$ \\ 1dyahnurula@gmail.com \\ 1,2,3 Universitas Islam Kadiri
}

Received: 0208 2019. Revised: 1808 2019. Accepted: 29082019

\begin{abstract}
Jenang dumbleg is one type of wet food that have storage duration was very short so its often to producers have to losses their products not sold off quickly. We need to the processing continuation of this product to of increasing age to keep from jenang dumbleg, traditional foods typical kecamatan gondang kabupaten nganjuk .One processing that easy and a lot of favored consumers is made it into the shape of chips .The activity was done in 4 stage, namely socialization to producers, skills training about processing jenang dumbleg, skills training the procedure of making jenang dumbleg chips, skills training about the technology packaging. The outcome of the activities can be seen that producers can make jenang dumbleg that good and were it being flaky jenang dumbleg having the value organoleptik good and acceptable for consumers.
\end{abstract}

Keywords: Dumbleg, Chips, Gondang, Jenang, Traditional

\begin{abstract}
Abstrak: Jenang dumbleg merupakan salah satu jenis pangan semi basah sehingga memiliki umur simpan yang singkat. Umur penyimpanan jenang dumbleg yang singkat tersebut menyebabkan seringkali produsen harus merugi jika produknya tidak laku terjual dengan cepat. Maka perlu adanya pengolahan lanjutan dari produk ini untuk meningkatkan umur simpan dari Jenang dumbleg, makanan tradisional khas Kecamatan Gondang Kabupaten Nganjuk. Salah satu pengolahan yang mudah dan banyak disukai konsumen adalah menjadikannya menjadi bentuk keripik. Kegiatan ini dilakukan dalam 4 tahapan, yaitu sosialisasi kepada produsen, pelatihan ketrampilan tentang pengolahan jenang dumbleg, pelatihan ketrampilan cara pembuatan keripik jenang dumbleg, pelatihan ketrampilan tentang teknologi pengemasan. Hasil kegiatan dapat dilihat bahwa produsen dapat membuat jenang dumbleg yang baik dan konsisten serta dapat menjadikannya menjadi keripik jenang dumbleg yang memiliki nilai organoleptik yang baik dan dapat diterima konsumen.
\end{abstract}

Kata Kunci: Dumbleg, Gondang, Jenang, Keripik, Tradisional

\section{ANALISIS SITUASI}

Jenang dumbleg merupakan makanan sejenis jenang yang terbuat dari tepung beras, santan kelapa dan gula dengan atau tanpa penambahan bahan lainnya yang diizinkan (SNI, 1992). Jenang dumbleg biasanya dihidangkan dalam berbagai kesempatan seperti pada acara 


\section{Jurnal ABDINUS : Jurnal Pengabdian Nusantara, 3 (1), 2019, 20-29}

Dyah Nurul Afiyah, Riska Nurtantyo Sarbini, Ahsin Daroini

hajatan dan menjamu tamu. Selain itu fungsi jenang adalah sebagai makanan kecil, sebagai teman minum teh (Astawan, 1991). Jenang dumbleg merupakan salah satu jenis pangan semi basah yang memiliki aktivitas air $\left(\mathrm{a}_{\mathrm{w}}\right)$ berkisar 0,70-0,90. Adanya aktivitas air ini dikarenakan dalam jenang terkandung kadar air kira-kira 15-50\%. Dengan adanya kandungan air ini, jenang memiliki kandungan air yang dapat membantu proses dehidrasi dan rehidrasi sehingga lunak dan lezat (Buckle, 1987).

Proses pengolahan jenang dumbleg dilakukan pada suhu tinggi dalam waktu yang lama mengakibatkan oksidasi lemak sejak awal. Oksidasi lemak berlanjut selama pengolahan dan penyimpanan. Dengan demikian terjadilah penurunan mutu jenang dumbleg selama penyimpanan akibat penstiwa ketengikan (rancidity) yang terjadi pada makanan berkadar lemak tinggi rnaupun rendah (Tanhindarto, 1998). Selain resiko ketengikan, jenang dumbleg tradisional dipasarkan dalam keadaan setengah terbuka karena hanya sebagian yang ditutupi pelepah pinang. Hal ini menyebabkan potensi kerusakan oleh mikroorganisme semakin besar, sehingga dumbleg memiliki umur simpan yang relatif singkat. Mikroba yang tumbuh pada produk pangan semi basah setelah disimpan beberapa hari adalah Aspergillus sp., Rhizopus sp., dan sebagian Penicillium. Dengan adanya pertumbuhan mikroba ini berarti produk pangan semi basah telah mengalami kerusakan. Kerusakan jenang dumbleg karena kapang merupakan masalah yang sering dihadapi dalam pendistribusian jenang dumbleg. Faktor penyebabnya adalah pengolahan yang kurang bersih maupun pengemasan dan penyimpanan yang kurang baik (Noer, 2006).

Umur penyimpanan jenang dumbleg yang singkat tersebut menyebabkan seringkali produsen harus merugi jika produknya tidak laku terjual dengan cepat. Maka perlu adanya pengolahan lanjutan dari produk ini untuk meningkatkan umur simpan dari Jenang dumbleg, makanan tradisional khas Kecamatan Gondang Kabupaten Nganjuk. Salah satu pengolahan yang mudah dan banyak disukai konsumen adalah menjadikannya menjadi bentuk keripik.

\section{SOLUSI DAN TARGET}

Keripik merupakan makanan ringan atau camilan berupa irisan tipis yang sangat popular di kalangan masyarakat karena sifatnya yang renyah, gurih, dan tidak terlalu mengenyangkan (Sriyono, 2012). Keripik sangat praktis karena kering sehingga lebih awet dan mudah disajikan kapan pun. Cara pengolahan keripik dumbleg dapat melalui penggorengan manual. Meskipun sederhana, melalui proses pengolahan yang tepat keripik jenang dumbleg dapat bertahan hingga berbulan-bulan tanpa bahan pengawet. 
Pengolahan dumbleg tersebut dilakukan di usaha rumahan milik Ibu Suparmi yang terdapat di Dusun Ngemplak, Desa Gondang Kulon, Kecamatan Gondang Kabupaten Nganjuk. Usaha tersebut dirintis sejak tahun 1998 diawali dengan membuat sesuai pesanan pelanggan. Namun, mulai tahun 2001, Ibu Suparmi mulai memiliki lapak jualan di Pasar Gondang Kabupaten Nganjuk dan memproduksi $\pm 10 \mathrm{~kg}$ tepung ketan setiap harinya. Usaha pembuatan jenang dumbleg ini masih dilakukan dengan tradisional, dengan menggunakan wajan diatas kompor kayu bakar sehingga produk yang dihasilkan terkadang memiliki warna dan kekentalan yang tidak konsisten. Selain itu, jenang dumbleg masih dikemas dengan pelepah pinang yang setengah terbuka, sehingga produk bercita rasa manis tersebut akan basi dalam waktu 3 hari.

Proses pengolahan jenang dumbleg menjadi keripik dilakukan setelah pengirisan dengan alat pengiris khusus agar keripik jenang dumbleg memiliki ketebalan yang sama. Setelah itu, adonan digoreng untuk mendapatkan tingkat kerenyahan yang pas dan disukai. Pasar masih terbuka luas dan bahan baku cukup tersedia, sehingga sangat perlu dilakukan sosialisasi, pelatihan, pembinaan dan bantuan fasilitas produksi agar produk keripik jenang dumbleg yang dihasilkan lebih berkualitas, tahan lama, mempunyai jaminan keamanan produk dan menjangkau pasar yang lebih luas sehingga dapat meningkatkan pendapatan masyarakat.

\section{METODE PELAKSANAAN}

Metode yang dilakukan dalam kegiatan ini dibagi dalam beberapa tahap, yaitu:

1. Tahap I. Dilakukan sosialisasi kepada mitra mengenai keuntungan dan manfaat mengolah jenang dumbleg menjadi produk keripik jenang dumbleg, pengemasan produk, penggunaan teknologi informasi dalam pemasaran produk secara on line, pencatatan keuangan usaha, dan jaminan keamanan produk.

2. Tahap II. Diadakan pelatihan ketrampilan kepada mitra tentang pengolahan jenang dumbleg menjadi produk keripik yang berkualitas secara fisik dan organoleptik.

3. Tahap III. Diberikan pelatihan ketrampilan cara pembuatan keripik jenang dumbleg menggunakan alat pengaduk jenang dumbleg, pemotong keripik dan penggorengan, serta perawatannya kepada mitra sehingga mereka mampu mengoperasikan dan melakukan perawatan secara mandiri. 
4. Tahap IV. Diadakan pelatihan ketrampilan kepada mitra tentang teknologi pengemasan produk jenang dumbleg, survey pasar dan teknik memasarkan produk secara on line.

\section{HASIL DAN LUARAN}

1. Tahap I

Salah satu produsen jenang dumbleg yang masih bertahan di Desa Gondang Kulon Kecamatan Gondang Kabupaten Nganjuk adalah Ibu Suparmi. Beliau memproduksi jenang dumbleg di dapur rumahnya dengan peralatan dapur seadanya. Lokasi dapur sendiri jadi satu dengan kamar mandi dengan beralaskan tanah dan beratapkan genteng tua. Hal ini dikhawatirkan dapat menimbulkan kontaminasi dari berbagai sumber. Adapun tempat produsi Ibu Suparmi dapat dilihat pada Gambar 1 dan 2.

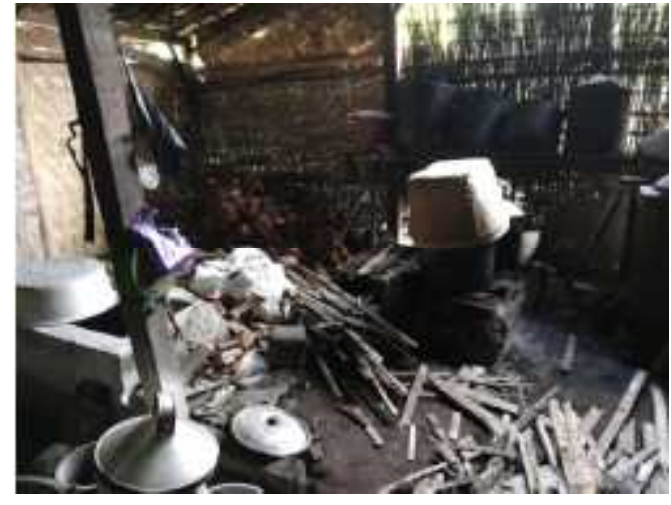

Gambar 1. Tempat Pengolahan

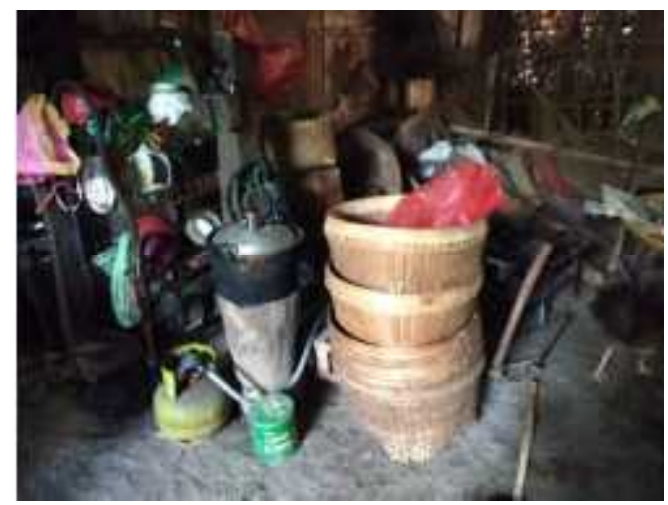

Gambar 2. Alat Pengolahan

Setelah kegiatan ceramah, produsen jenang dumbleg telah mengetahui dan menerapkan pemisahan terhadap bahan baku dan bahan jadi, serta semua peralatannya. Produsen mengetahui dan menerapkan system First In First Out (FIFO) terhadap bahan baku yang disimpan dalam tempat produksinya.

Tahap I ini produsen jenang dumbleg juga diberikan pengetahuan mengenai bahaya yang akan terjadi jika produk yang tidak terjual dalam 1 hari dihangatkan kemudian dijual kembali.Mengingat bahaya dan kerugian yang akan terjadi, maka perlu adanya pengolahan menjadi produk turunan yang lebih awet dan mudah dilakukan dengan peralatan sederhana. Produk tersebut salah satu contohnya adalah keripik jenang dumbleg.

\section{Tahap II}

Produsen jenang dumbleg sudah mulai memproduksi dumbleg selama turun temurun. Namun, hingga garis keturunan ketiga ini, belum memiliki patokan resep yang sama. Semua tergantung pada ketersediaan bahan, sehingga terkadang menghasilkan 


\section{Jurnal ABDINUS : Jurnal Pengabdian Nusantara, 3 (1), 2019, 20-29}

Dyah Nurul Afiyah, Riska Nurtantyo Sarbini, Ahsin Daroini

produk yang berbeda baik warna, rasa maupun tekstur. Kesempatan ini, produsen diberi tahu untuk menjaga kualitas produk dimulai dari menggunakan bahan baku yang seragam.

Jenang dumbleg membutuhkan bahan baku berupa tepung beras, santan, gula merah dan garam. Tepung beras yang digunakan pada akhirnya berasal dari beras yang diproduksi sendiri dari sawah keluarga yang ditepungkan sebelum proses pembuatan jenang dumbleg dimulai. Santan berasal dari kelapa yang tua karena dipercaya mampu menghasilkan santan dengan jumlah yang lebih banyak. Gula yang digunakan adalah gula aren yang berukuran besar dan berwarna cokelat tua.

Bahan utama yang menjadi ciri khas pada jenang dumbleg adalah pelepah pinang. Pelepah pinang yang digunakan adalah pelepah pinang yang tua dan lebar. Pelepah pinang diambil dari perkebunan di daerah Kecamatan Rejoso dan dipotong ukuran 20 x $20 \mathrm{~cm}$, kemudian dijahit sebelah pinggirnya dengan menggunakan tali dan jarum. Proses pengambilan pelepah pinang dilakukan seminggu sekali untuk menjaga agar pelepah tersebut tidak terlalu lama kemudian kering dan sulit digunakan.

Prosedur pengolahan $10 \mathrm{~kg}$ jenang dumbleg yang baik dan disukai konsumen dapat dilihat pada gambar berikut ini.

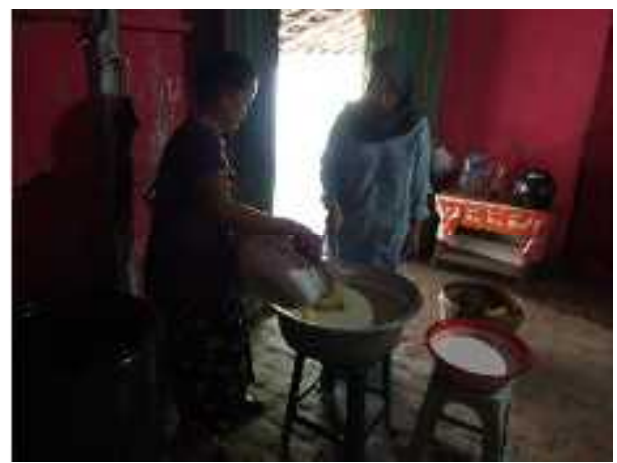

Gambar 3. Pencampuran bahan

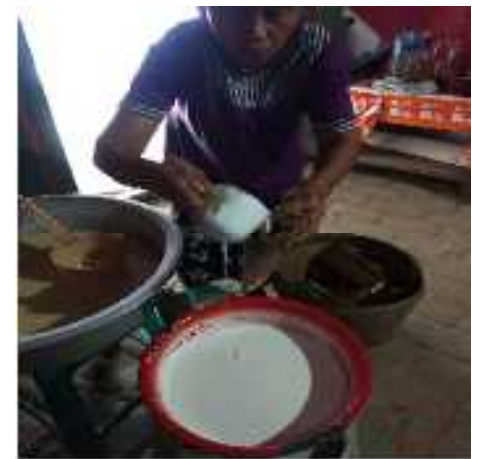

Gambar 4. Pencetakan

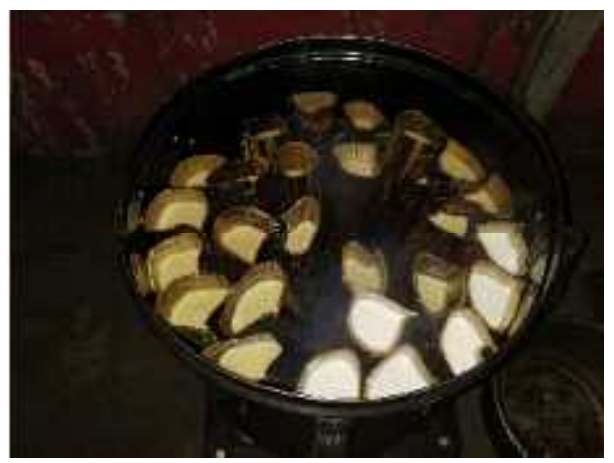

Gambar 5. Proses Pembuatan 
Jurnal ABDINUS : Jurnal Pengabdian Nusantara, 3 (1), 2019, 20-29

Dyah Nurul Afiyah, Riska Nurtantyo Sarbini, Ahsin Daroini

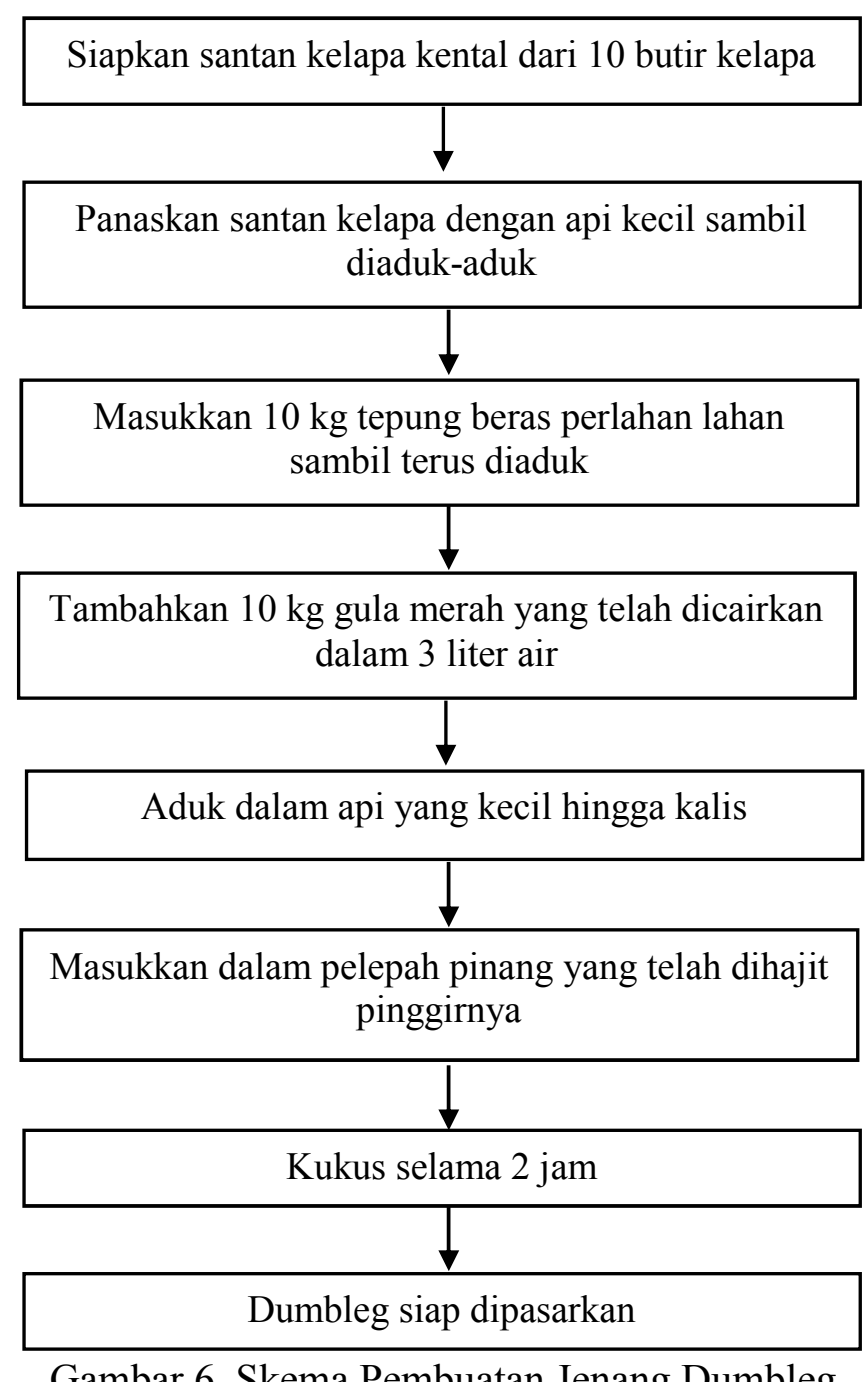

3. Tahap III

Gambar 6. Skema Pembuatan Jenang Dumbleg

Umur penyimpanan jenang dumbleg yang singkat tersebut menyebabkan seringkali produsen harus merugi jika produknya tidak laku terjual dengan cepat. Maka perlu adanya pengolahan lanjutan dari produk ini untuk meningkatkan umur simpan dari Jenang dumbleg, makanan tradisional khas Kecamatan Gondang Kabupaten Nganjuk. Salah satu pengolahan yang mudah dan banyak disukai konsumen adalah menjadikannya menjadi bentuk keripik.

Keripik merupakan makanan ringan atau camilan berupa irisan tipis yang sangat popular di kalangan masyarakat karena sifatnya yang renyah, gurih, dan tidak terlalu mengenyangkan (Sriyono, 2012). Keripik sangat praktis karena kering sehingga lebih awet dan mudah disajikan kapan pun. Cara pengolahan keripik dapat dilihat pada Gambar 7. 
Jurnal ABDINUS : Jurnal Pengabdian Nusantara, 3 (1), 2019, 20-29

Dyah Nurul Afiyah, Riska Nurtantyo Sarbini, Ahsin Daroini

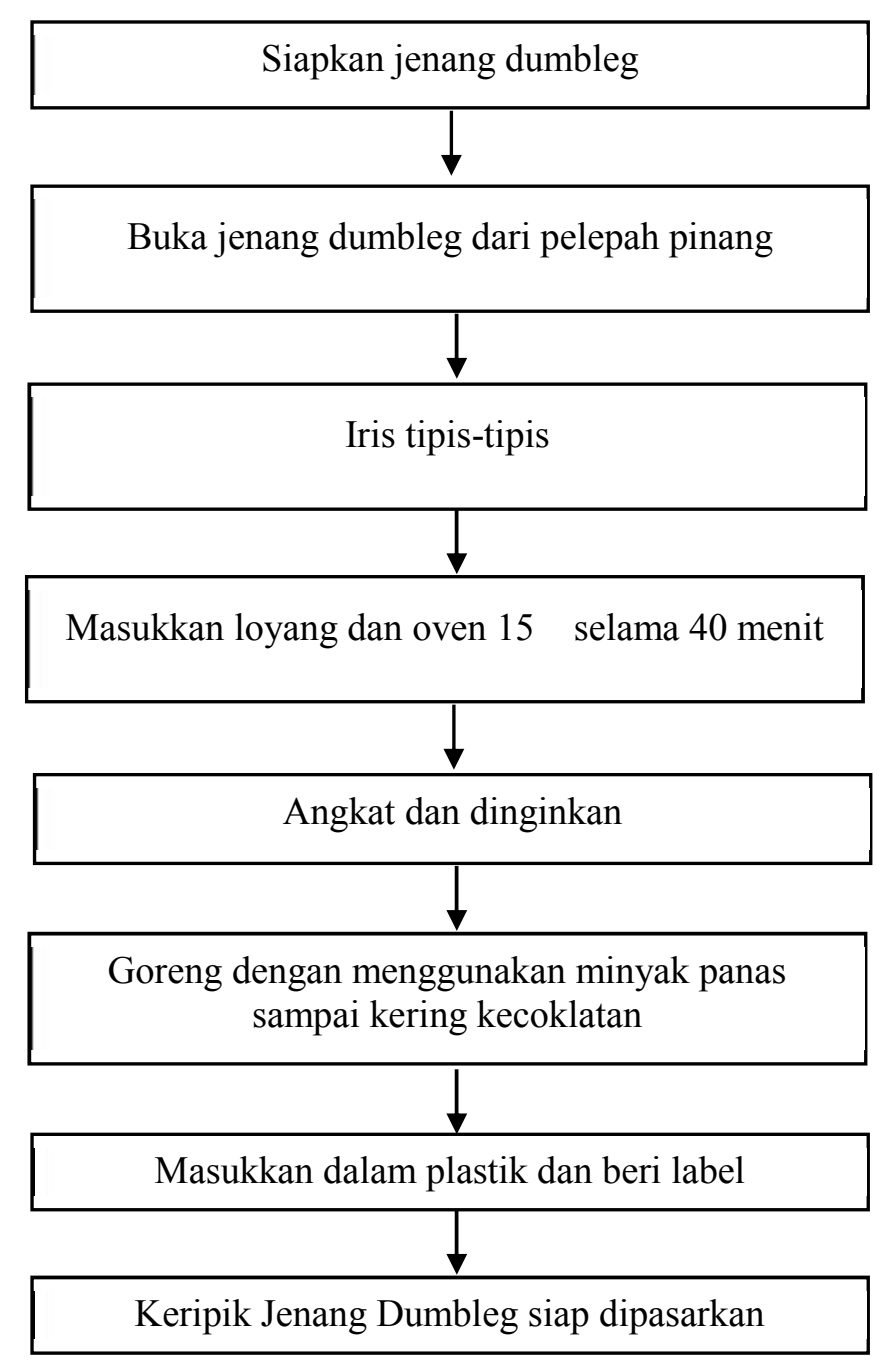

Gambar 7. Skema Pembuatan Keripik Jenang Dumbleg

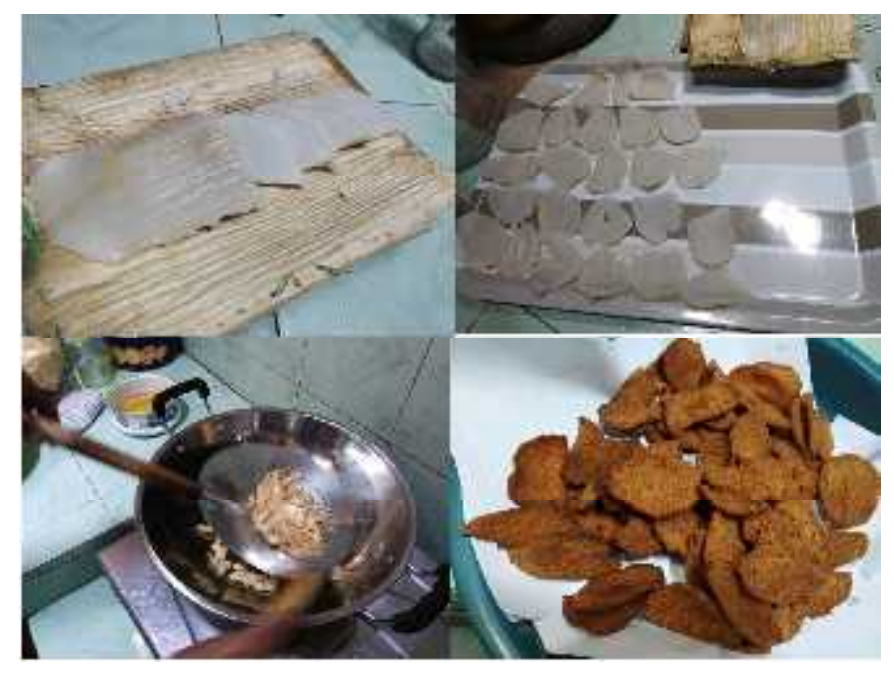

Gambar 8. Pembuatan Keripik Jenang Dumbleg 
Keripik Jenang Dumbleg yang dihasilkan kemudian diuji secara organoleptik untuk mengetahui mutu dan tingkat kesukaan konsumen terhadap produk ini. Sampel keripik diuji oleh 30 panelis tidak terlatih dan hasilnya dapat dilihat sebagai berikut:

Tabel 1. Hasil Uji Mutu Hedonik Keripik Jenang Dumbleg

Keterangan:

\begin{tabular}{|l|c|c|c|c|}
\hline & Warna & Aroma & Rasa & Kerenyahan \\
\hline $\begin{array}{l}\text { Keripik } \\
\text { Jenang } \\
\text { Dumbleg }\end{array}$ & 3,3 & 2,8 & 3,1 & 2,9 \\
\hline
\end{tabular}

Warna

: 1. Putih; 2. Kuning; 3. Coklat; 4. Hitam

Aroma

: 1. Tidak beraroma jenang; 2. Agak beraroma jenang; 3. Beraroma Jenang;

4. Sangat beraroma jenang

Rasa

: 1. Tidak berasa jenang; 2. Agak berasa jenang; 3. Berasa Jenang;

4. Sangat berasa jenang

Kerenyahan : : 1. Alot; 2. Agak renyah; 3. Renyah; 4. Sangat renyah

Hasil pengujian mutu hedonik menjelaskan bahwa keripik dumbleg memiliki warna cenderung cokelat, beraroma jenang, berasa jenang dan renyah ketika dikonsumsi. Sedangkan penujian hedonik ataupun kesukaan hasilnya dapat dilihat pada Tabel 5.

Tabel 2. Hasil Uji Hedonik Keripik Jenang Dumbleg

\section{Keterangan:}

\begin{tabular}{|l|c|c|c|c|}
\hline & Warna & Aroma & Rasa & Kerenyahan \\
\hline $\begin{array}{l}\text { Keripik } \\
\text { Jenang } \\
\text { Dumbleg }\end{array}$ & 2,7 & 3,2 & 3,2 & 3,4 \\
\hline
\end{tabular}

1. Tidak suka; 2. Agak suka; 3. Suka; 4. Sangat Suka

Hasil uji hedonik atau kesukaan menggambarkan bahwa keripik jenang dumbleg yang dihasilkan disukai oleh konsumen dengan parameter warna, aroma, rasa dan kerenyahan.
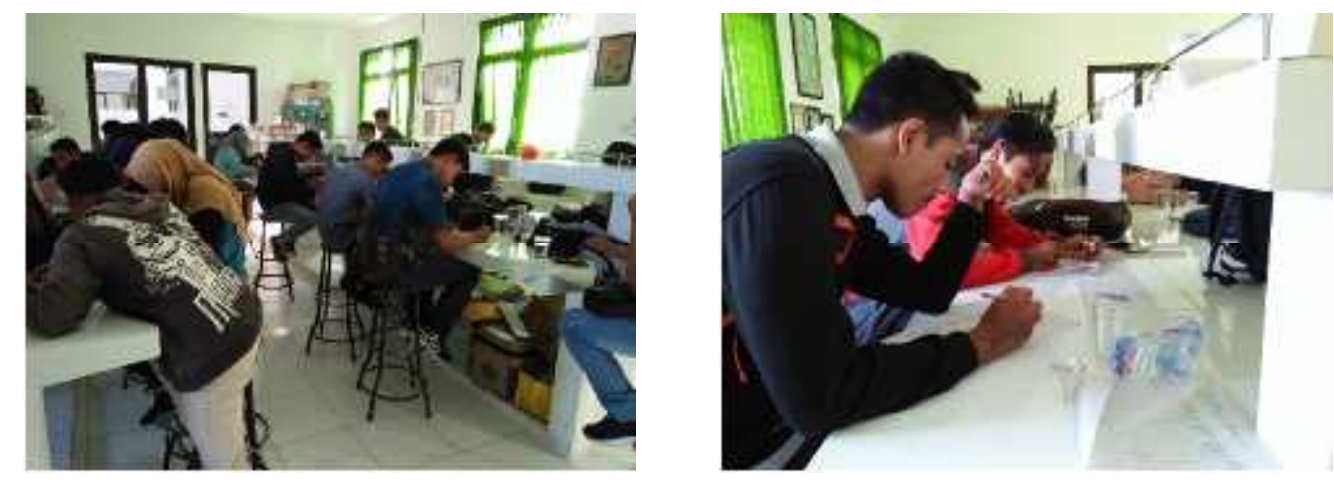

Gambar 9. Uji Organoleptik Keripik Jenang Dumbleg 


\section{Jurnal ABDINUS : Jurnal Pengabdian Nusantara, 3 (1), 2019, 20-29}

Dyah Nurul Afiyah, Riska Nurtantyo Sarbini, Ahsin Daroini

\section{Tahap IV}

Keripik Jenang Dumbleg yang telah diproduksi perlu dikemas dengan baik untuk meningkatkan ketertarikan konsumen akan produk yang dihasilkan serta melindungi produk dari ancaman fisik, kimia dan mikrobiologi. Produk dikemas dalam standing pouch untuk mendapatkan produk yang aman, awet dan memiliki daya tarik tinggi di mata konsumen. Produk kemudian diberi label yang berisi informasi sebagai berikut: merk, produsen, alamat produsen, netto, tanggal produksi, tanggal kadaluarsa dan komposisi produk.
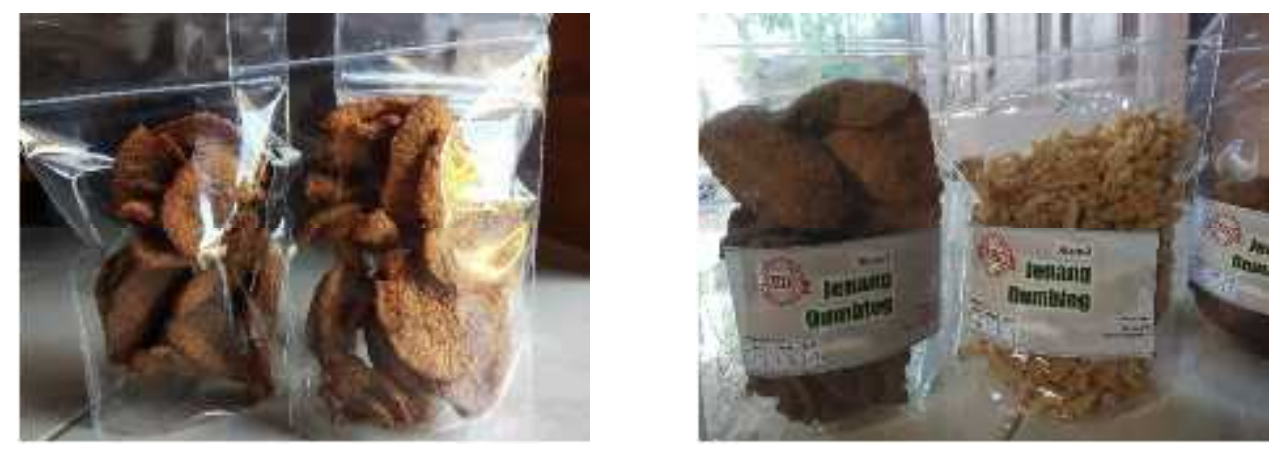

Gambar 10. Kemasan Keripik Jenang Dumbleg

\section{SIMPULAN}

Jenang Dumbleg yang baik dibuat dengan perbandingan bahan tepung beras: gula merah: kelapa $=1: 1: 1$. Keripik Jenang Dumleg dibuat dari jenang dumbleg yang diiris kemudian dioven lalu digoreng. Keripik Jenang Dumbleg memiliki mutu yang baik dan disukai konsumen dibuktikan melalui uji organoleptik. Keripik Jenang Dumbleg yang telah jadi segera dikemas dan diberi label

\section{DAFTAR RUJUKAN}

Astawan dan Wahyuni. 1991. Teknologi Pengolahan Nabati Tepat. Bogor: Akademik Pressindo.

Badan Pusat Statistik Jawa Timur. 2010. Statistik Indonesia Tahun 2010. Jakarta Pusat : Badan Pusat Statistik

Badan Pusat Statistik Jawa Timur. 2011. Statistik Indonesia Tahun 2011. Jakarta Pusat : Badan Pusat Statistik

Badan Pusat Statistik Jawa Timur. 2013. Statistik Indonesia Tahun 2013. Jakarta Pusat : Badan Pusat Statistik 
Buckle, K, A., R, A Edwards, G, H., Flett, M., Wootton. 1987. Ilmu Pangan. Universitas Indonesia. Jakarta. dikutip dari Yustina Ita. 2012. Pengaruh Penambahan Aneka Rempah Terhadap Sifat Fisik, Organoleptik serta Kesukaan Pada Kerupuk dari Susu Sapi Segar. Fakultas Pertanian Universitas Trunojoyo Madura. Madura.

Idrus, Haryati. 1994. Pembuatan Dodol.Balai Besar Penelitian Pengembangan Industri Hasil Pertanian. Depertemen Industri.

Jamaluddin, dkk. 2011. Pengaruh Suhu dan Tekanan Vakum Terhadap Penguapan Air, Perubahan Volume Dan Rasio Densitas Keripik Buah Selama Dalam Penggorengan Vakum. Makassar: Fakultas Teknik Universitas Negeri Makasar.

Noer, Hendry. 2006. Mengenal Dodol Secara Ilmiah. http:/www.foodreview.biz. Diakses pada tanggal 7 Januari 2015 pada pukul 13.25 WIB.

Sriyono, 2012. Pembuatan Keripik Umbi Talas (Colocasia Gigantueum) dengan Variabel Lama Waktu Penggorengan Menggunakan Alat Vacuum Fraying.Tugas Akhir Program Diploma Fakultas Teknik Universitas Diponegoro:Semarang

Tanhindarto, R. P. (1998). Mempertahankan Mutu Makanan Tradisional Dodol Kombinasi Iradiasi Dan Pengemas Modifikasi Atmosfer. Penelitian Dan Pengembangan Aplikasi Isotop Dan Radiasi, 161-167. 